MACHADO, R. de M. (2020)

Metodologias ativas e tecnologias digitais como potencializadoras do processo de ensino-aprendizagem no Ensino Médio Integrado

\title{
Metodologias ativas e tecnologias digitais como potencializadoras do processo de ensino-aprendizagem no Ensino Médio Integrado
}

\author{
Active methodologies and digital technologies as enhancers of the teaching- \\ learning process in integrated high school
}

\author{
MACHADO, Ricardo de Macedo. Discente do curso de Mestrado em Educação \\ Profissional e Tecnológica \\ Instituto Federal de Educação Ciência e Tecnologia do Sertão Pernambucano- IF Sertão Campus Salgueiro. \\ Salgueiro - PE - Brasil. / E-mail: ricardomacedomachado@gmail.com
}

\section{RODRIGUES, Adriana de Carvalho Figueiredo. Doutora em Engenharia Agrícola} Instituto Federal de Educação Ciência e Tecnologia do Sertão Pernambucano- IF Sertão Campus Salgueiro. Salgueiro - PE - Brasil / E-mail: adriana.figueiredo@ifsertaope.edu.br

\section{RESUMO}

$\mathrm{O}$ artigo trata do processo de ensino-aprendizagem na Educação Profissional e Tecnológica (EPT), com ênfase no Ensino Médio Integrado (EMI). Discute-se a respeito da implementação de metodologias ativas e uso das Tecnologias Digitais de Informação e Comunicação (TDICs) no processo educativo, compreendidas, respectivamente, como estratégias inovadoras e recursos/ferramentas indispensáveis à educação contemporânea. Assim, este trabalho tem como objetivo analisar e discutir os benefícios e desafios de efetivação das metodologias ativas e das tecnologias digitais para o processo de ensino-aprendizagem no EMI. O estudo é de natureza qualitativa, constituindo-se a partir de pesquisa bibliográfica. Nesse contexto, esse estudo verificou que, repensar e reelaborar os processos e estratégias de ensino-aprendizagem constitui ação fundamental das instituições de ensino e profissionais da educação, especialmente os(as) professores(as), para o alcance de uma educação crítica, contextualizada e libertadora. Assim como, no âmbito da EPT, especificamente no EMI, é importante que o(a) professor(a) possa proporcionar espaços de aprendizagem que favoreçam a atividade (participação ativa) do aluno, assim como uma educação integradora a partir da união entre teoria e prática como também entre formação geral e formação técnica, sempre com foco na preparação para a cidadania e para o mundo do trabalho, tendo como eixos estruturantes da sua prática a cultura, o trabalho, a ciência e a tecnologia. Conclui-se que a implementação de metodologias ativas no EMI, assim como a utilização pedagógica das TDICs como ferramentas mediadoras dos processos de ensino e aprendizagem, constituem importantes estratégias para o fortalecimento da aprendizagem, da autonomia e do protagonismo estudantil.

Palavras-chave: Educação Profissional e Tecnológica. Aprendizagem ativa. Autonomia. Protagonismo estudantil.

\begin{abstract}
The article deals with the teaching-learning process in Vocational and Technological Education (EPT), with an emphasis on Integrated High School (EMI). It discusses the implementation of active methodologies and the use of Digital Information and Communication Technologies (TDICs) in the educational process, understood, respectively, as innovative strategies and resources / tools indispensable to contemporary education. Thus, this work aims to analyze and discuss the benefits and challenges of implementing active methodologies and digital technologies for the teaching-learning process at EMI. The study is of a qualitative nature, constituting from bibliographic research. In this context, this study found that rethinking and re-elaborating the teaching-learning processes and strategies is a fundamental action of educational institutions and education professionals, especially teachers, in order to achieve critical, contextualized education. and liberating. As well, within the scope of EFA, specifically in EMI, it is important that the teacher can provide learning spaces that favor the student's activity (active participation), as well as an integrative education based on the union between theory and practice as well as between general and technical training, always with a focus on preparing for citizenship and the world of work, with culture, work, science and technology as the structuring axes of its practice. It is concluded that the implementation of active methodologies in EMI, as well as the pedagogical use of TDICs as mediating tools in the teaching and learning processes, are important strategies for strengthening learning, autonomy and student leadership.

Keywords: Professional and Technological Education. Active learning. Autonomy. Student leadership.
\end{abstract}


MACHADO, R. de M. (2020)

Metodologias ativas e tecnologias digitais como potencializadoras do processo de ensino-aprendizagem no Ensino Médio Integrado

\section{Introdução}

São inúmeros os desafios que os sistemas educacionais, instituições de ensino e professores enfrentam, dentre os quais podemos destacar os de ordem curricular, de gestão administrativa e pedagógica, de práticas e metodologias de ensino, abandono e evasão escolar, entre outros.

Diante de tais desafios, no que compete ao campo das práticas didático-pedagógicas e à atuação docente, é imprescindível que o processo de ensino e aprendizagem nos mais diferentes níveis e modalidades de ensino ocorra a partir de estratégias e metodologias inovadoras, que possibilite superar práticas pedagógicas bancárias centradas no professor e no conteúdo, e que permita deslocar o foco do processo educativo para o aluno e para a construção de seu projeto de vida.

Nesse contexto, na Educação Profissional e Tecnológica (EPT), especificamente no Ensino Médio Integrado (EMI), é importante que gestores, professores e comunidade escolar possam refletir acerca das práticas de ensino, uma vez que não basta saber o que deve ser ensinado, mas, também, como deve ser ensinado e para quê. Assim, urge a necessidade de implementação de estratégias didático-metodológicas que possam favorecer a aprendizagem ativa e significativa do educando, a exemplo das metodologias ativas com mediação tecnológica.

As metodologias ativas constituem estratégias pedagógicas que possibilitam deslocar o aluno para o centro do processo de ensino-aprendizagem, favorecendo a sua participação ativa na construção do conhecimento. São inúmeros os métodos considerados ativos, a exemplo da sala de aula invertida, da aprendizagem baseada em problemas, da aprendizagem baseada em projetos, da instrução por pares, do estudo de caso etc. Todos eles possibilitam ao educador despertar no aluno o gosto e interesse em aprender, desenvolvendo sua autonomia e protagonismo.

Nessa direção, a educação para o século XXI demanda professores dispostos a aprender a aprender, a inovar, a buscar as melhores estratégias pedagógicas que possam contribuir para a formação do educando. Requer, também, considerar as novas Tecnologias Digitais de Comunicação e Informação (TDICs) como meios/ferramentas que podem potencializar a aprendizagem a partir das inúmeras possibilidades de pesquisas, comunicação, colaboração e interpretação da realidade com base em múltiplas linguagens (escrita, música, imagem, vídeo, games etc.).

Tendo como eixo central de investigação essas novas possibilidades de ensinar e aprender, o presente estudo tem por objetivo analisar e discutir os benefícios e desafios de efetivação das metodologias ativas e das tecnologias digitais para o processo de ensino-aprendizagem no EMI. Para tal fim, buscou-se apoio e fundamentação em obras e escritos de autores que abordam as temáticas e problemáticas aqui levantadas, a exemplo de Bacich (2018), Camargo e Daros (2018), Ciavatta (2014), Freire (2011), Moran (2004, 2015, 2018), Moura (2013), entre outros.

É, portanto, na direção de estimular debates e reflexões acerca da prática docente no EMI no contexto da educação contemporânea, que este estudo procurou contribuir para um maior entendimento acerca da necessidade de aprimoramento e inovação do fazer pedagógico, o que pode favorecer a construção de cenários educativos mais próximos da realidade e anseios dos jovens educandos do século XXI. 
MACHADO, R. de M. (2020)

Metodologias ativas e tecnologias digitais como potencializadoras do processo de ensino-aprendizagem no Ensino Médio Integrado

\section{Metodologias ativas: o ensino e a aprendizagem}

Nas últimas décadas, no meio educacional, tem ganhado corpo discussões válidas e pertinentes acerca da necessidade de se (re)pensar e (re)elaborar as práticas de ensino e atuação pedagógica dos professores, no sentido de superar métodos tradicionais caracterizados pelo transmissionismo de conteúdos e centralidade nos educadores. Estratégias didáticas focadas no aluno e em suas dificuldades de aprendizagem, na personalização do ensino, na construção de competências e habilidades duradouras, na pedagogia contextualizada (FREIRE, 2011) e na participação ativa do educando no processo educativo, têm sido apontadas como meios de inovar as aulas e fortalecer os processos formativos.

No centro dessas estratégias didático-pedagógicas inovadoras estão as metodologias ativas, que, apesar da sua contemporaneidade e importância como prática pedagógica, tem suas matrizes conceituais datadas do início do século XX, a partir das reflexões e escritos de autores como John Dewey e Kilpatrick (DAROS, 2018). De acordo com Moran (2018, p. 4), as metodologias ativas constituem "[...] estratégias de ensino centradas na participação efetiva dos estudantes na construção do processo de aprendizagem, de forma flexível, interligada e híbrida [...]". 0 autor afirma que:

[...] As metodologias ativas, num mundo conectado e digital, expressam-se por meio de modelos de ensino híbridos, com muitas possíveis combinações. A junção de metodologias ativas com modelos flexíveis e híbridos traz contribuições importantes para o desenho de soluções atuais para os aprendizes de hoje. (MORAN, 2018, p. 4)

$\mathrm{Na}$ sociedade do conhecimento, globalizada, marcada pela crescente circulação de informações a partir dos meios tecnológicos digitais, é possível que professores e alunos possam combinar diferentes métodos de ensino-aprendizagem com mediação das tecnologias digitais, o que constitui cenários educativos híbridos e flexíveis. Essas novas possibilidades de configuração das salas de aula e das práticas didático-pedagógicas fazem com que docentes e discentes possam trabalhar em conjunto, de forma colaborativa, para a construção do conhecimento.

Althaus e Bagio (2017) apontam que nas metodologias ativas de ensino-aprendizagem a atuação do professor e do aluno muda completamente. 0 docente deixa de ser um mero transmissor de informações e passa a ser um mediador e designer de caminhos educativos diversos que atendam as demandas e dificuldades de aprendizagem do aluno. Cabe ao educando, nesse processo, assumir, também, a responsabilidade por sua aprendizagem, sugerindo, indagando, pesquisando e colaborando para a construção coletiva do saber.

Corroborando com esse pensamento, Camargo (2018, p. 15) afirma que "as metodologias ativas de aprendizagem colocam o aluno como protagonista, ou seja, em atividades interativas com os outros, aprendendo e se desenvolvendo de modo colaborativo." 0 trabalho pedagógico a partir de métodos ativos permite ao professor criar situações de aprendizagem nas quais os educandos possam fazer coisas, pensar e conceituar o que fazem, fornecer e receber feedback, sempre de forma críticoreflexiva, assim como aprender a interagir com seus pares e docente, possibilitando explorar atitudes 
MACHADO, R. de M. (2020)

Metodologias ativas e tecnologias digitais como potencializadoras do processo de ensino-aprendizagem no Ensino Médio Integrado

e valores pessoais (VALENTE, 2018).

Seguindo nessa mesma linha de pensamento, Freire (2011) afirma que o educador deve buscar desenvolver uma prática pedagógica democrática, procurando sempre reforçar a capacidade crítica do aluno, a sua curiosidade e insubmissão. Para o autor, aprender criticamente exige “[...] a presença de educadores e educandos criadores, instigadores, inquietos, rigorosamente curiosos, humildes e persistentes" (FREIRE, 2011, p. 28).

Percebe-se, a partir do entendimento dos autores supracitados, que as metodologias ativas, se bem planejadas e implementadas no ambiente escolar, podem potencializar a aprendizagem do aluno, dinamizar e inovar as aulas, flexibilizar processos e estreitar a comunicação entre os envolvidos no cotidiano da sala de aula e/ou fora dela. Possibilitam, ainda, fomentar a autonomia discente, sua capacidade de investigar, analisar e propor soluções para diferentes problemas da realidade que os envolvem.

O trabalho pedagógico embasado em metodologias ativas pode se tornar ainda mais frutífero quando combinado às TDICs, a partir da utilização de diferentes linguagens e ferramentas conectadas à internet, a exemplo do audiovisual, da utilização de aplicativos, games, Ambientes Virtuais de Aprendizagem (AVA), redes sociais etc. Assim, na próxima seção, tentaremos analisar e discutir a importância das TDICs para a aprendizagem ativa.

\section{Tecnologias digitais para a aprendizagem ativa}

De acordo com Moran (2004), os alunos de hoje não aguentam mais o modelo tradicional de aulas. Eles reclamam da rigidez dos horários, do tédio de ficar ouvindo o professor transmitir informações por horas, da distância entre os conteúdos lecionados e a vida real. Para o autor, a educação atingiu um nível de defasagem tão alto, que não adianta adotar medidas paliativas. É preciso revolucionar a forma como se dá aula.

Considerando que as tecnologias digitais invadiram o nosso cotidiano, a exemplo da internet, do smartphone, das redes sociais, aplicativos etc., entendemos que tais recursos podem ser aproveitados pedagogicamente nos processos de ensino e aprendizagem, constituindo meios possíveis de revolucionar e inovar a prática educativa. "Os avanços constantes das TDICs têm exigido dos sistemas educacionais a formação de um cidadão do/para o mundo, capacitado a empregar os novos recursos tecnológicos para a aquisição e construção de conhecimento" (ANDRADE; FERRETE, 2019 , p. 87).

Nesse contexto, a construção de competências (cognitivas, profissionais, socioemocionais etc.) e habilidades (atitudes e valores) (BRASIL, 2017) pelos alunos, perpassa, também, pelo mínimo domínio e utilização das novas tecnologias disponíveis. Para isso, as escolas e professores precisam considerar em suas práticas pedagógicas estratégias de ensino-aprendizagem que possibilitem aos educandos manusear e testar diferentes ferramentas tecnológicas, aproximando o ensino da realidade.

Corroborando com esse pensamento, Toledo, Moreira e Nunes (2017, p. 111), apontam que integrar as TDICs ao processo educativo "significa agregar valores à linguagem de alunos que vivem 
MACHADO, R. de M. (2020)

Metodologias ativas e tecnologias digitais como potencializadoras do processo de ensino-aprendizagem no Ensino Médio Integrado

em uma sociedade caracterizada como pós-moderna, atuante e conectada."

Os alunos de hoje - do maternal à faculdade - representam as primeiras gerações que cresceram com esta nova tecnologia. Eles passaram a vida inteira cercados e usando computadores, videogames, tocadores de música digitais, câmeras de vídeo, telefones celulares, e todos os outros brinquedos e ferramentas da era digital [...]. (PRENSKY, 2001, p. 1)

Nesse sentido, é evidente que a inserção das novas tecnologias no processo educativo aproximará o aluno da sua realidade, das ferramentas e recursos com os quais já é familiarizado, o que contribuirá para potencializar a sua aprendizagem e aumentar a sua motivação. "Promover atividades que estimulem o desejo dos alunos de aprender é muito importante [...]. Um aluno motivado com conteúdos dinâmicos e interativos aprenderá e assimilará, muito melhor, os conceitos trabalhados" (GARCÍA; ORTEGA; ZEDNIK, 2017, p. 47).

Para Bergmann e Sams (2019), adotar os recursos digitais como ferramentas pedagógicas significa falar a língua dos alunos, aproximá-los dos objetos e conteúdos de estudo considerando seus conhecimentos prévios e, por fim, motivá-los a aprender a aprender.

As tecnologias são só apoio, meios. Mas elas nos permitem realizar atividades de aprendizagem de formas diferentes às de antes. Podemos aprender estando juntos em lugares distantes, sem precisarmos estar sempre juntos numa sala para que isso aconteça. Podemos planejar mudanças graduais, flexibilizando o currículo, diminuindo o número de aulas presenciais, combinando-as com atividades em laboratórios conectados à Internet e com atividades a distância. (MORAN, 2004, p. 2)

Considerando as palavras de Moran, é importante deixar claro que os recursos tecnológicos digitais constituem meios que podem potencializar o processo educativo, não podendo ser vistos/tidos como a panaceia para todos os problemas da educação. Sendo assim, as TDIC jamais substituirão o papel do professor no espaço escolar, pois o conhecimento se constrói a partir das interações entre os homens e destes para com seu meio.

Diante do exposto, compreendemos que no campo da EPT, especificamente no EMI, o processo educativo demanda uma aprendizagem significativa, contextualizada, interdisciplinar e orientada para o uso das TDICs, possibilitando a construção de habilidades para a resolução de problemas no mundo do trabalho e para a cidadania (BARBOSA; MOURA, 2013).

Portanto, cabe-nos entender e caracterizar O EMI para que possamos compreender a relevância das metodologias ativas e das TDICs nesta modalidade de ensino.

\section{Metodologias ativas e tecnologias digitais no Ensino Médio Integrado (EMI)}

O Ensino Médio corresponde à etapa final da Educação Básica, constituindo direito público subjetivo de todo cidadão brasileiro (BRASIL, 2017). 0 art. 36-A da Lei n 9.394/1996, Lei de Diretrizes e Bases da Educação Nacional (LDB), estabelece que o ensino médio, atendida a formação geral do educando, poderá prepará-lo para o exercício de profissões técnicas. Assim, de acordo com o art. 36- 
MACHADO, R. de M. (2020)

Metodologias ativas e tecnologias digitais como potencializadoras do processo de ensino-aprendizagem no Ensino Médio Integrado

C da mesma lei, uma das formas de oferta do ensino médio profissionalizante é o EMI, o qual possibilita ao educando habilitação profissional técnica de nível médio na mesma instituição de ensino e com matrícula única.

Observando a legislação sobre o tema e considerando as diversas realidades educacionais do Brasil, Moura (2013) entende que o EMI constitui uma necessidade para o país, pois possibilita materializar um tipo de educação que objetiva uma base unitária de conhecimentos para todos, fundamentada na premissa de formação humana integral ou politécnica. Para Ciavatta (2014), a formação integrada representa mais que uma forma de articulação entre o Ensino Médio e a Educação Profissional. Ela significa a luta por uma educação democrática e unitária, ou seja, que possibilite a superação do dualismo educacional (formação manual versus formação intelectual) da sociedade brasileira, assim como a garantia de uma escola pública, inclusiva, laica e de qualidade. Nesse sentido, o EMI se configura como possibilidade de transformação positiva da educação e da sociedade a partir do comprometimento ético-político-pedagógico de todos.

$\mathrm{Na}$ direção do que apontam Moura e Ciavatta, as Diretrizes Curriculares Nacionais para a Educação Profissional Técnica de Nível Médio (Resolução CNE/CEB 6/2012) estabelecem que os cursos do EMI devem proporcionar ao educando “conhecimentos, saberes e competências profissionais necessários ao exercício profissional e da cidadania, com base nos fundamentos científicotecnológicos, sócio-históricos e culturais" (BRASIL, 2012). Ainda de acordo com as diretrizes supracitadas, são princípios norteadores da Educação Profissional Técnica de Nível Médio (EPTNM), entre outros: assumir o trabalho como princípio educativo e a pesquisa como princípio pedagógico; a indissociabilidade entre educação e prática social; e a efetivação de um trabalho pedagógico interdisciplinar, flexível e contextualizado.

Considerando a necessidade de efetivação dessas diretrizes, Barbosa e Moura (2013) apontam que as discussões e avaliações realizadas sobre o EMI têm focalizado questões de organização curricular e percursos formativos, e com menor ênfase aspectos que tratam de metodologias inovadoras que possibilitem aos educandos a construção de habilidades pessoais e profissionais. Para os autores, é importante que as instituições de ensino e seus educadores possam não só reformular seus currículos e percursos formativos, mas, também, viabilizar novas práticas e metodologias de ensino que possam proporcionar a formação crítico-reflexiva do aluno, aproximando conhecimento teórico e prático, formação técnica e formação geral conforme preconiza as diretrizes.

Apontando nessa direção, Andrade e Ferrete (2019) argumentam que é necessário considerar as metodologias ativas como novos métodos de ensino-aprendizagem no EMI, às quais, se bem planejadas e implementadas, podem contribuir para a superação de práticas pedagógicas tradicionais às quais já estamos acostumados. Para eles, é imprescindível, também, considerar os novos recursos tecnológicos para uma aprendizagem com mais autonomia, flexibilidade e interatividade.

Moran (2004) aponta que as tecnologias digitais trouxeram novas possibilidades de ensinar e de aprender, presencialmente ou a distância, possibilitando a alunos e professores uma maior cooperação para a construção do saber. Para o autor, na atual sociedade do conhecimento, sociedade em rede, as salas de aula serão, “cada vez mais, um ponto de partida e de chegada, um espaço importante, mas que se combina com outros espaços para ampliar as possibilidades de atividades de 


\section{Revista Semiárido De Visu}

MACHADO, R. de M. (2020)

Metodologias ativas e tecnologias digitais como potencializadoras do processo de ensino-aprendizagem no Ensino Médio Integrado

aprendizagem" (MORAN, 2004, p. 3).

Em estudo realizado no segundo semestre de 2017 com alunos do curso técnico em Agropecuária integrado ao Ensino Médio, do Instituto Federal de Educação, Ciência e Tecnologia de Mato Grosso do Sul (IFMS), Turina et al. (2019) evidenciam os benefícios das metodologias ativas e das TDICs para o processo educativo no EMI. Segundo os autores, a implementação de metodologias ativas e tecnologias digitais nas aulas de desenho técnico, como a sala de aula invertida, a aprendizagem baseada em projetos etc., favoreceu o desenvolvimento e aprimoramento de competências pelos educandos, como a oralidade, o senso de responsabilidade, a capacidade de trabalhar coletivamente para solucionar problemas, a autonomia e protagonismo, assim como a utilização de recursos tecnológicos digitais para produzir e difundir conhecimentos.

Conforme os autores supracitados, a utilização de metodologias ativas associadas às tecnologias digitais no EMI proporciona aos alunos e professores a descoberta de novos saberes, o aprender a aprender e a capacidade de se completarem para produzir novos conhecimentos de forma ativa e colaborativa. Corroborando com esse pensamento, Rodrigues (2016), aponta que:

Com o uso de aprendizagens ativas e estratégias de ensino, que variam desde atividades baseadas em projetos, resolução de problemas e tantas outras, o aluno passa a exercer um papel vital na criação de novos conhecimentos que servirão de base para a sua vida acadêmica e profissional [...]. (RODRIGUES, 2016, p. 28)

Destarte, Moran (2015) nos lembra que as metodologias de ensino precisam acompanhar os objetivos educacionais pretendidos. Segundo o autor, se quisermos que os alunos sejam proativos e criativos, verdadeiros “detetives" do conhecimento, é fundamental adotarmos estratégias metodológicas que os envolvam em atividades cada vez mais complexas, para que possam avaliar processos e tomar decisões coerentes com a realidade dada, sempre com o apoio do professor e com instrumentos e materiais relevantes.

A utilização de metodologias ativas e das TDICs no EMI, além de promover a motivação dos alunos para a aprendizagem, possibilita ao professor "sistematizar a integração entre as áreas da formação geral e técnica, bem como entre as disciplinas no âmbito das próprias áreas de conhecimentos" (COSTA; COUTINHO, 2019, p. 11).

Diante do exposto, é possível afirmarmos que a utilização de metodologias ativas e de tecnologias digitais no EMI representa um grande desafio para professores e alunos, porém, também se constitui possibilidade de inovação da prática pedagógica e incentivo importante para a aprendizagem ativa e significativa pelos educandos.

\section{Material e métodos}

O presente estudo, de natureza qualitativa, teve caráter eminentemente bibliográfico. Conforme Gil (2002), a pesquisa bibliográfica é desenvolvida a partir de materiais já elaborados, como artigos científicos, dissertações, teses e livros, por exemplo. 


\section{Revista Semiárido De Visu}

MACHADO, R. de M. (2020)

Metodologias ativas e tecnologias digitais como potencializadoras do processo de ensino-aprendizagem no Ensino Médio Integrado

Assim, o levantamento dos textos que embasam esta pesquisa ocorreu nos portais Periódicos Capes, Google Acadêmico e Scielo, utilizando-se descritores variados, como metodologias ativas, Ensino Médio Integrado, Educação Profissional e Tecnológica, tecnologias digitais na educação, formação integral, entre outros. Buscou-se selecionar, entre os arquivos encontrados, àqueles que mais se relacionavam com a temática em questão e com o objetivo do estudo, totalizando 27 trabalhos, compreendendo o período de 2014 a 2019.

Em seguida, optou-se por discorrer, inicialmente, acerca do que são metodologias ativas e sua importância para a educação contemporânea, expondo e interagindo com o pensamento de autores relevantes, a exemplo de Moran (2018) e Camargo (2018). Na sequência, tratou-se da importância das tecnologias digitais no contexto da aprendizagem ativa.

Por fim, buscou-se evidenciar a utilização das metodologias ativas e das tecnologias digitais no EMI à luz de autores diversos, a exemplo de Andrade e Ferrete (2019), Barbosa e Moura (2013), Moran (2004, 2015), Turina et al. (2019), entre outros.

\section{Resultados e discussão}

De acordo com o levantamento bibliográfico, considerando os descritores da pesquisa, verificou-se que do total de publicações selecionadas (27), 7 foram dos Periódicos Capes, 12 do Google Acadêmico e 8 do Scielo. A Tabela 1 apresenta o percentual de trabalhos encontrados nas diferentes fontes de pesquisas utilizadas que apresentaram relevância para o estudo.

Tabela 1. Percentual de publicações selecionadas nas fontes de pesquisas utilizadas, considerando os descritores.

\begin{tabular}{|c|c|}
\hline Fontes de Publicação & \% de publicações selecionadas \\
\hline Artigos científicos & 82 \\
\hline Livros & 8 \\
\hline Dissertações & 6 \\
\hline Teses & 4 \\
\hline Total & 100 \\
\hline
\end{tabular}

Fonte: Os autores (2020).

Destaca-se o predomínio de artigos científicos (82\%) sobre as demais fontes de publicação: livros $(8 \%)$, dissertações $(6 \%)$ e teses $(4 \%)$. Pela natureza e tipo de pesquisa adotada neste estudo, optou-se por priorizar, como base de fundamentação teórica, artigos científicos, pois considera-se que os mesmos apresentam em seu conteúdo uma visão mais detalhada, objetiva e atual acerca das temáticas aqui levantadas.

$\mathrm{Na}$ Tabela 2 verifica-se o percentual de distribuição de trabalhos com base nos descritores da pesquisa. Os números evidenciam o predomínio de trabalhos com as temáticas metodologias ativas (32\%) e tecnologias digitais na educação (28\%). Os demais descritores de pesquisa também 
MACHADO, R. de M. (2020)

Metodologias ativas e tecnologias digitais como potencializadoras do processo de ensino-aprendizagem no Ensino Médio Integrado

apresentaram significativa relevância para a composição do estudo: educação profissional e tecnológica e ensino médio integrado (15\% cada) e formação integral (10\%).

Tabela 2. Percentual de distribuição de trabalhos com base nos descritores da pesquisa.

\begin{tabular}{|c|c|}
\hline Descritores da Pesquisa & $\%$ \\
\hline Metodologias ativas & 32 \\
\hline Tecnologias digitais na educação & 28 \\
\hline Educação profissional e tecnológica & 15 \\
\hline Ensino médio integrado & 15 \\
\hline Formação integral & 10 \\
\hline Total & 100 \\
\hline
\end{tabular}

Fonte: Os autores (2020).

Considerando a temática proposta neste estudo, foi dada ênfase à análise acerca da utilização de metodologias ativas combinadas às TDICs no contexto do EMI com vistas à superação de práticas tradicionais e bancárias de ensino. Conforme os números apresentados, percebe-se a grande importância e discussão acerca da inserção de novas metodologias e recursos tecnológicos para potencializar o processo de ensino-aprendizagem no EMI. Tais estratégias são apontadas como essenciais para a inovação da prática docente e motivação dos educandos.

Assim, diante da investigação teórica realizada, foi possível constatar a unanimidade entre os autores acerca da necessidade de transformação e atualização das práticas didático-pedagógicas no EMI, no sentido de contextualizar aquilo que se ensina, assim como promover uma educação inovadora, flexível e colaborativa, aspectos importantes para a formação do jovem do século XXI (BRASIL, 2017). Para tal fim, compreende-se que as metodologias ativas combinadas às TDICs constituem importantes meios/estratégias de inovação, motivação e formação educacional (ANDRADE; FERRETE, 2019).

Em relação à utilização de metodologias ativas no EMI, verificou-se o grande potencial das práticas ativas para a consecução do objetivo maior dessa modalidade de ensino, que é contribuir para a formação integral/omnilateral/politécnica do educando (CIAVATTA, 2014; MOURA, 2013). A partir da efetivação de metodologias ativas, é possível dar mais autonomia e liberdade ao aluno, fazendo com que o mesmo se sinta mais motivado para aprender e, consequentemente, desenvolver seu pensamento crítico e criativo (BARBOSA; MOURA, 2013).

Em relação à mediação dos processos de ensino e aprendizagem no EMI, percebeu-se que as TDICs constituem importantes recursos/ferramentas para auxiliar e facilitar o compartilhamento de informações entre professores e alunos e destes para com seus pares, ampliando as possibilidades de aprendizagem a partir da construção coletiva de novos conhecimentos (MORAN, 2018). Nesse sentido, a implementação de metodologias ativas ancoradas nas TDICs, que, no seu conjunto, preconizam a participação ativa do aluno no processo ensino-aprendizagem, constituem importante caminho para 
MACHADO, R. de M. (2020)

Metodologias ativas e tecnologias digitais como potencializadoras do processo de ensino-aprendizagem no Ensino Médio Integrado

a dinamização da prática educativa com vistas à superação de práticas tradicionais e bancárias de ensino (FREIRE, 2011).

Para que as metodologias ativas produzam resultados satisfatórios no EMI, é imprescindível que o docente reelabore seu planejamento, mude de postura diante da nova realidade educacional que ora se desenha para o século XXI, realidade esta, marcada pela ubiquidade, colaboração e flexibilidade dos processos educativos (CAMARGO; DAROS, 2018). Também entendemos que para que as TDICs se constituam em um diferencial no processo ensino-aprendizagem, é importante que o educador esteja disposto a aprender como utilizá-las pedagogicamente. É necessário que esteja aberto ao novo, ou seja, se faz necessário aprender a aprender em um processo contínuo de formação (CAPALONGA; WILDNER, 2018).

A aplicação de metodologias ativas combinadas às TDICs não pode ocorrer de maneira aleatória, ou seja, sem a definição de critérios. Assim, a depender do conteúdo a ser estudado/trabalhado em sala de aula, se faz necessário ter claro entendimento dos objetivos a serem alcançados para, a partir deste ponto, traçar as melhores estratégias para o alcance desses mesmos objetivos (MORAN, 2015).

[...] o uso de diferentes metodologias ativas é importante e trazem benefícios para os estudantes nas mais diversas áreas. Destaca-se que a escola profissionalizante tem um papel fundamental e transformador no desenvolvimento das capacidades do futuro profissional e na construção do seu conhecimento, como também capacitá-los a refletir e analisar criticamente a sociedade de que fazem parte, tornando-os cidadãos pensantes. (CAPALONGA; WILDNER, p. 159)

Percebe-se, então, que as utilizações de metodologias ativas combinadas às TDICs na EPT, especificamente no EMI, contribuem significativamente para o fortalecimento da formação do educando em suas múltiplas dimensões (cognitiva, profissional etc.) e, consequentemente, para a construção do seu projeto de vida (BRASIL, 2017).

Portanto, conclui-se que o processo de ensino-aprendizagem fundamentado em métodos ativos e ancorado em tecnologias digitais estimula e potencializa a interação entre entre os atores envolvidos na prática educativa (professor e aluno), contribuindo para a construção de competências e habilidades indispensáveis para o aprimoramento do senso crítico dos indivíduos, assim como para a preparação para o mundo do trabalho e exercício da cidadania.

\section{Conclusões}

O estudo procurou contribuir para a análise e discussão acerca dos desafios e possibilidades inerentes à EPT na contemporaneidade, com ênfase em questões relativas às práticas didáticopedagógicas e metodológicas nos processos de ensino e aprendizagem no EMI.

Para a construção dessa reflexão, sempre inconclusa e inesgotável porque dinâmica e histórica, buscou-se fundamentação em autores consagrados em matéria de educação, a exemplo de Bacich (2018), Ciavatta (2014), Freire (2006), Moran (2004, 2015, 2018), Moura (2013), entre outros. 


\section{Revista Semiárido De Visu}

MACHADO, R. de M. (2020)

Metodologias ativas e tecnologias digitais como potencializadoras do processo de ensino-aprendizagem no Ensino Médio Integrado

Assim, discutiu-se a respeito da efetivação de metodologias ativas com mediação das TDICs nos processos de ensino e aprendizagem na modalidade médio integrado à educação profissional, destacando-se os principais desafios e benefícios inerentes à prática docente e formação do educando.

A análise evidenciou que a utilização de metodologias ativas combinadas às tecnologias digitais representa possibilidades de inovação do fazer docente, ampliando o leque de caminhos/estratégias para a construção da aprendizagem pelos educandos.

Percebeu-se também que o trabalho pedagógico fundamentado em métodos ativos e com mediação tecnológica aumenta a motivação e empenho dos alunos, favorecendo o desenvolvimento de um trabalho educativo mais flexível (ajustado às necessidades de aprendizagem do educando), colaborativo e formativo.

Por outro lado, constatou-se também a necessidade de abertura e formação do professor para esta nova realidade que ora se desenha, o que implica, entre outras questões, superar práticas bancárias e acríticas de ensino, assim como fazer uso de novas linguagens e ferramentas, a exemplo das TDICs, para potencializar as aprendizagens.

Portanto, conclui-se que fazer educação de qualidade é uma tarefa complexa, especificamente no EMI, porém, no que compete à prática docente desenvolvida no chão da sala de aula, se faz necessário utilizar novos métodos de ensino-aprendizagem e lançar mão de novas tecnologias que de fato contribuam para a formação e emancipação do aluno.

\section{Referências}

ALTHAUS, Maiza Taques Margraf; BAGIO, Viviane Aparecida. As metodologias ativas e as aproximações entre o ensino e a aprendizagem na prática pedagógica universitária. Revista Docência Do Ensino Superior, v. 7, n. 2, p. 79-96, 2017.

ANDRADE, Luiz Gustavo da Silva Bispo; FERRETE, Rodrigo Bozi. Metodologias ativas e a educação profissional e tecnológica. Educação Profissional e Tecnológica em Revista, v. 3, n. 2, p. 86-98, 2019.

BARBOSA, Eduardo Fernandes; MOURA, Dácio Guimarães de. Metodologias ativas de aprendizagem na educação profissional e tecnológica. Boletim Técnico do Senac, v. 39, n. 2, p. 48-67, 2013.

BERGMANN, Jonathan.; SAMS, Aaron. Sala de aula invertida: uma metodologia ativa de aprendizagem. Tradução: Afonso Celso da Cunha Serra. - $1^{\text {a }}$.ed. - [Reimpr.]. - Rio de Janeiro: LTC, 2019.

BRASIL. Lei $\mathrm{n}^{\circ}$ 13.415/2017. Base Nacional Comum Curricular (BNCC). Documento homologado pela Portaria $n^{\circ}$ 1.570, publicada no D.O.U. de 21/12/2017, Seção 1, Pág. 146. Ministério da Educação MEC, Brasília, 2017. Disponível em: <http://basenacionalcomum.mec.gov.br/>. Acesso em: 20 mar. 2020.

Lei $n^{\circ}$ 9394/1996. Lei de Diretrizes e Bases da Educação Nacional (LDB). Brasília, 20 de dezembro de 1996. Disponível em: <http://www.planalto.gov.br/ccivil_03/leis/l9394.htm>. Acesso em: 20 ago. 2020. 


\section{Revista Semiárido De Visu}

MACHADO, R. de M. (2020)

Metodologias ativas e tecnologias digitais como potencializadoras do processo de ensino-aprendizagem no Ensino Médio Integrado

Resolução CNE/CEB 6/2012. Diretrizes Curriculares Nacionais para a Educação Profissional Técnica de Nível Médio. Diário Oficial da União, Brasília, 21 de setembro de 2012, Seção 1, p. 22. Disponível em:

<http: / / portal.mec.gov.br/index.php?option=com_docman\&view=download\&alias=11663-rceb00612-pdf\&category_slug=setembro-2012-pdf\&Itemid=30192 >. Acesso em: 20 abr. 2020.

CAMARGO, Fausto. Por que usar metodologias ativas de aprendizagem? In: CAMARGO, F.; DAROS, T. A sala de aula inovadora: estratégias pedagógicas para fomentar o aprendizado ativo. Porto Alegre: Penso, 2018. p. 13-17.

CAPALONGA, Flávia; WILDNER, Maria Claudete Schorr. Usando as metodologias ativas na educação profissional: identificação, compreensão e análise nas percepções dos estudantes. Revista Destaques Acadêmicos, v. 10, n. 4, 2018.

CIAVATTA, Maria. O ensino integrado, a politecnia e a educação omnilateral. Por que lutamos?/The integrated education, the polytechnic and the omnilateral education. Why do we fight?. Trabalho \& Educação-ISSN 1516-9537/e-ISSN 2238-037X, v. 23, n. 1, p. 187-205, 2014.

COSTA, Maria Adélia; COUTINHO, Eduardo Henrique Lacerda. Metodologias ativas e currículo integrado: a travessia para as práticas pedagógicas motivadoras na educação profissional técnica de nível médio. Boletim Técnico do Senac, v. 45, n. 3, 2019.

DAROS, Thuinie. Metodologias ativas: aspectos históricos e desafios atuais. In: CAMARGO, F.; DAROS, T. A sala de aula inovadora: estratégias pedagógicas para fomentar o aprendizado ativo. Porto Alegre: Penso, 2018. p. 8-12.

FREIRE, Paulo. Pedagogia da autonomia: saberes necessários à prática educativa. Paz e Terra, 2011.

GARCÍA, Camino López; ORTEGA, Carlos Alberto Catalina; ZEDNIK, Herik. Realidade Virtual e Aumentada: Estratégias de Metodologias Ativas nas Aulas sobre Meio Ambiente. Informática na educação: teoria \& prática, v. 20, n. 1 jan/abr, 2017.

GIL, Antônio Carlos. Como elaborar projetos de pesquisa. - 4. ed. - São Paulo: Atlas, 2002.

MORAN, José. Metodologias ativas para uma aprendizagem mais profunda. In: BAClCH, L. (Org.); MORAN, J (Org.). Metodologias ativas para uma educação inovadora: uma abordagem teórico-prática. Porto Alegre: Penso, 2018. p. 1-25.

MORAN, José Manuel. Propostas de mudança nos cursos presenciais com a educação on-line. Revista da ABENO, v. 5, n. 1, p. 40-45, 2004.

MORÁN, José. Mudando a educação com metodologias ativas. Coleção mídias contemporâneas. Convergências midiáticas, educação e cidadania: aproximações jovens, v. 2, n. 1, p. 15-33, 2015. 


\section{Revista Semiárido De Visu}

MACHADO, R. de M. (2020)

Metodologias ativas e tecnologias digitais como potencializadoras do processo de ensino-aprendizagem no Ensino Médio Integrado

MOURA, Dante Henrique. Ensino médio integrado: subsunção aos interesses do capital ou travessia para a formação humana integral?. Educação e Pesquisa, v. 39, n. 3, p. 705-720, 2013.

PRENSKY, Marc. Nativos digitais, imigrantes digitais. Tradução de Roberta de Moraes Jesus de Souza. On the horizon, v. 9, n. 5, p. 1-6, 2001.

RODRIGUES, Glaucemária da Silva. Análise do uso da metodologia ativa Problem Based Learning (PBL) na educação profissional. Outras Palavras, v. 12, n. 2, 2016.

TOLEDO, Jenifer Vieira; MOREIRA, Ucineide Rodrigues Rocha; NUNES, Andrea Karla. 0 uso de metodologias ativas com TIC: uma estratégia colaborativa para o processo de ensino e aprendizagem. Simpósio Internacional de Educação e Comunicação-SIMEDUC, n. 8, 2017.

TURINA, Agnaldo Nogueira et al. Utilização de metodologia ativa no ensino de desenho técnico do curso técnico em agropecuária integrado ao ensino médio do IFMS: avaliação de estudantes. Encontro Internacional de Gestão, Desenvolvimento e Inovação (EIGEDIN), v. 3, n. 1, 2019.

VALENTE, José Armando. A sala de aula invertida e a possibilidade do ensino personalizado: uma experiência com a graduação em midialogia. In: BACICH, L. (Org.); MORAN, J. (Org.). Metodologias ativas para uma educação inovadora: uma abordagem teórico-prática. Porto Alegre: Penso, 2018. p. 26-44. 